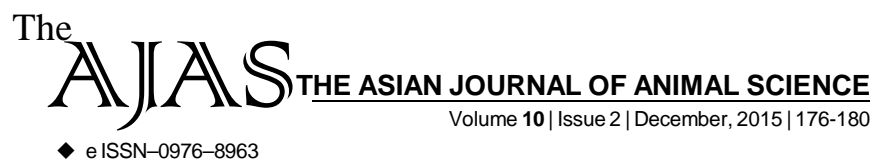

DOI : 10.15740/HAS/TAJAS/10.2/176-180 Visit us | www.researchjournal.co.in $\mathbf{S}$

\title{
Goals of livestock innovation related activities of scientists and extensionists in Veterinary and Animal Science Universities
}

PRAKASHKUMAR RATHOD AND MAHESH CHANDER

PRAKASHKUMAR RATHOD AND MAHESH CHANDER $\cdots \cdots \cdots$

Author for Corresponding -

PRAKASHKUMAR RATHOD Department of Veterinary and Animal Husbandry Extension, Veterinary College, BIDAR (KARNATAKA) INDIA

Email: prakashkumarkr@

gmail.com

See end of the article for

Coopted authors'

\begin{abstract}
The present study was carried out to identify different goals of livestock innovation related activities of four veterinary and animal science universities in North India. Further, the study also made an attempt to know the perceived satisfaction level of the respondents with regards to the activities performed in the universities. The data was collected from scientists and extensionists of four Universities and Institutes in North India through questionnaire and discussion. The study indicated that, majority of the scientists perceived that their university aimed to generate own income and reduce the labour costs and also responded that they were more satisfied with the goal of increasing commodity quality and generate own income compared to other activities. Further, majority of the extension experts perceived that their organization aimed to provide knowledge and information and generate own income, while they also reported that goal of providing knowledge and information and introducing new products or processes was considered more satisfactory than other activities. Although, all the goals of activities were equally important, only few of the activities were highly performed in the universities. Hence, there is a need to analyse the importance of each activities and perform them for suitable impact to the farming community. There is also an urgent need to improve upon the quality of these activities performed in the universities by scientists and extensionists so that farming community can be satisfied accordingly.
\end{abstract}

KEY WORDS...... Scientists, Extension, Livestock innovations, Livestock technologies, Veterinary universities, Animal science universities

HOW TO CITE THIS ARTICLE - Rathod, Prakashkumar and Chander, Mahesh (2015). Goals of livestock innovation related activities of scientists and extensionists in Veterinary and Animal Science Universities. Asian J. Animal Sci., 10(2): 176-180.

ARTICLE CHRONICLE - Received : 31.07.2015; Revised : 15.11.2015; Accepted : 21.11.2015 